Article

\title{
Evaluation on the Corrosion and Wear Properties of C-Fibers Doped Aluminum Coatings Obtained Using Arc Spray Technolgoy
}

\author{
Su Fang ${ }^{1}$, Jingzhong Zhou ${ }^{1}$, Songqiang Huang ${ }^{2}$, Zhaowei Hu ${ }^{3, *}$ and Wenge $\mathrm{Li}^{3, *}$ \\ 1 EHV Transmission Company, China Southern Power Grid Co., Ltd., Guangzhou 540000, China; \\ 15820236899@139.com (S.F.); zjzking@163.com (J.Z.) \\ 2 Liuzhou Bureau of EHV Transmission Company, China Southern Power Grid Co., Ltd., \\ Liuzhou 545006, China; foobarx@163.com \\ 3 Merchant Marine College, Shanghai Maritime University, Shanghai 201306, China \\ * Correspondence: huzw@shmtu.edu.cn (Z.H.); wgli@shmtu.edu.cn (W.L.)
}

Received: 13 October 2020; Accepted: 12 November 2020; Published: 16 November 2020

check for updates

\begin{abstract}
Aiming at the wear and corrosion problems of fittings in $500-\mathrm{kV}$ power transmission lines, a functional aluminum-based coating is prepared by an electric arc spraying process and self-made aluminum-based powder-cored wire. The experimental results showed that the friction coefficient of the coating is reduced from 0.4 to 0.2 after adding carbon fiber and that the wear rate is reduced from $2 \times 10^{-3}$ to $8 \times 10^{-4} \mathrm{~mm}^{3} /(\mathrm{N} \cdot \mathrm{m})$. The electrochemical behavior of the composite coating is similar to that of the pure aluminum coating. After a 720-h salt spray test, there is no obvious corrosion products on the coating surface, and the thickness of the corrosion layer is only $29 \mu \mathrm{m}$. The new composite coating not only has a good anti-wear effect, but also maintains good corrosion resistance of the aluminum coating.
\end{abstract}

Keywords: electric arc spraying; aluminum-based powder-cored wire; anti-corrosion; wear resistance

\section{Introduction}

Corrosion and wear are the two main causes of failure of parts materials for power grid applications exposed to harsh outdoor environments. A large-scale, easy to operate and low-cost surface protection technology is urgently required. Thermal spraying technology is widely used in the field of anti-corrosion [1]. Commonly used thermal spraying coatings include Al-based, Zn-based, and $\mathrm{Zn}$-Al-based corrosion-resistant coatings. Electric arc spray is one of the widely used thermal spray methods, which is extremely competitive in the field of long-term corrosion protection [2,3]. Relevant studies have shown that aluminum-based corrosion-resistant coatings have excellent corrosion resistance characteristics, and the protective effect can last for about 20 years [4-7]. Since it is easy to form a dense oxide film on its surface, the aluminum-based coating effectively blocks the infiltration of corrosive media and prevents further corrosion.

However, the pure aluminum coating exhibits insufficient comprehensive mechanical properties. Wear and tear will cause the change of the size of parts and ultimately cause failures. The continued operation of the equipment will cause safety hazards and loss of reliability. Due to its excellent corrosion resistance and easy adjustment of material composition, powder-cored arc spray coatings have occupied an important position in the fields of wear resistance, corrosion resistance, and high temperature-resistant protective coatings [8-10]. Sheppard et al. [11] used arc spraying powder core wire to prepare $\mathrm{NiCrBSi} / \mathrm{WC}$ and $\mathrm{NiBSi} / \mathrm{WC}$ coatings. The friction and wear test found that the NiBSi/WC coating exhibited better wear resistance. Although the content of WC/W2C in the 
$\mathrm{NiCrBSi} / \mathrm{WC}$ coating is higher, the solubility of the W element in the NiBSi coating is higher, which makes the wear resistance of NiBSi/WC coatings better. Functionalized aluminum-based coatings can not only retain the corrosion resistance of pure aluminum coatings but can also improve different characteristics by combining with different materials [12-16]. Owing to its simple operation and suitability for in situ large-area construction, the use of electric arc spraying aluminum-based coatings has significant economic advantages and it is suitable for industrial applications. Therefore, it is of great practical and economic significance to study aluminum-based powder core wires and to develop composite coatings using electric arc spraying technology.

In order to protect the aluminum-based coating against damage by friction and wear, the second phase that is introduced must possess stable friction and low wear to satisfy the varying and rigorous service conditions. Searching for novel friction materials without sacrificing the corrosion resistance of protective coatings has been a research focus in recent decades. Carbon fiber (CF)-reinforced metal matrix composites were developed and widely used due to the good self-lubricant properties, high specific strength, specific modulus, and electric conductivity [17,18]. Lei et al., [18] reported that the corrosion and wear resistances of Ni-based coatings can be improved effectively, which is attributed to the good properties and homogeneous distribution of $\mathrm{CF}$ and the finer microstructure of composite coatings. In this study, the arc sprayed $\mathrm{Al}$ coating was reinforced with $\mathrm{CF}$. The Al-CF coating was prepared by combining metal aluminum, which is often used for corrosion-resistant coating, and carbon fiber with an anti-friction effect, which has both anti-corrosion and anti-friction functions. It provides useful data for the usage of aluminum-carbon fiber composite materials in the field of corrosion and wear resistance.

\section{Materials and Methods}

The pure aluminum strip used for the production of wire is of grade 1060 with a size of $7 \mathrm{~mm} \times$ $0.4 \mathrm{~mm}$ (Hualv Aluminum, Dongguan, China). The carbon fibers are of 200 mesh with a sectional diameter of $6 \mu \mathrm{m}$ (Shanghai Lishuo Composite Material Technology, Shanghai, China). The substrate used for coating deposition is $20 \mathrm{~mm} \times 30 \mathrm{~mm} \times 2 \mathrm{~mm}$ Q235 steel sheet. The drawing machine equipment (FM5-LZ3/450-SG800) is from Jiayun Machinery Co., Ltd. (Nantong, China). The planetary ball mill (QM-3SP4) was manufactured by Nanjing University Instrument Factory (Nanjing, China).

The mass ratio of $\mathrm{Al}$ powder:carbon fiber was 1:1. Al powders and carbon fibers were mixed using a planetary ball mill for $5 \mathrm{~h}$ with a rotation speed of $400 \mathrm{rpm}$. Aluminum powder has a very strong plastic deformation ability in the ball milling process. In order to avoid shape change and poor fluidity of the feedstocks, no grinding ball was put in the ball milling tank.

Aluminum-based cored wire with Al-carbon fiber powders as filler was used as the feedstock for the arc spraying, and the obtained powder core wires were $2 \mathrm{~mm}$ in diameter (bandwidth of the aluminum velum: $7 \mathrm{~mm}$, thickness of the velum: $400 \mu \mathrm{m}$ ).

Q235 steel substrates were ultrasonically cleaned in acetone for $10 \mathrm{~min}$ to remove oil stains on the surface, then rinsed with deionized water, and dried in air. Abrasive blasting of a substrate prior to application of thermal spray coatings determines the adhesion and quality of the coating. Sand blasting was carried out using corundum powders of 60-200 $\mu \mathrm{m}$ with 7-bar compressed air. It was propelled with an impact angle of $\sim 90^{\circ}$ and target distance of about $150 \mathrm{~mm}$ for Q235 steel substrates. After surface roughening using a sandblasting machine, the coating was prepared using high-speed arc spraying equipment (Castolin-Eutectic Pte Ltd., Nashville, TN, USA). The thickness of the coating was about 300 500 $\mu \mathrm{m}$ by adjusting the number of sweeps. The thickness of the coating was about $300 \sim 500 \mu \mathrm{m}$ by adjusting the sweep passes from 40 to 80 . The arc spraying process parameters are shown in Table 1. 
Table 1. Arc spraying process parameters.

\begin{tabular}{cc}
\hline Process Parameter & Value \\
\hline Spraying voltage & $28 \sim 32 \mathrm{~V}$ \\
Spraying current & $80 \sim 110 \mathrm{~A}$ \\
Spraying distance & $150 \mathrm{~mm}$ \\
Compressed gas & Air \\
Spraying air pressure & $0.65 \mathrm{MPa}$ \\
Moving speed of spray gun & $300 \mathrm{~mm} / \mathrm{s}$ \\
Number of sweeps of spray gun & $40 \mathrm{n}$ \\
Wire feeding speed & $0.05 \mathrm{~m} / \mathrm{s}$ \\
\hline
\end{tabular}

According to the ASTM B117-2007 [19] standard, the neutral salt spray test was performed in a salt spray test chamber (model Q-FOG CCT-1100, Elyria, OH, USA). Epoxy was used to coat the back and around the coating samples, leaving only a working surface of $1 \mathrm{~cm}^{2}$ in the middle of the coating. At least 3 parallel samples were used for each sample. A salt solution containing $5 \% \pm 0.5 \%$ sodium chloride and a pH of 6.5 to 7.2 was used. The setting parameters of the salt spray test chamber are: the experimental temperature is $35 \pm 2{ }^{\circ} \mathrm{C}$, the humidity is greater than $95 \%$, the spray pressure is $1 \mathrm{~kg} / \mathrm{cm}^{2}$, and the amount of mist reduction is 1 to $2 \mathrm{~mL} /\left(\mathrm{h} \cdot \mathrm{cm}^{2}\right)$.

In order to further study the corrosion resistance of the composite coating, a three-electrode electrochemical test system (Modulab, Solartron, UK) was used to measure the electrochemical behavior of the coatings. The back of the sample was polished with sandpaper and then connected to a wire by soldering. Then, the periphery and back of the sample were sealed with epoxy resin, leaving only a $1 \mathrm{~cm}^{2}$ area on the front coating as the working surface. The saturated calomel electrode (SCE) was used as a reference electrode and immersed in a saturated $\mathrm{KCl}$ solution, and a $1-\mathrm{cm}^{2}$ platinum electrode as used as an auxiliary electrode and placed in parallel with the working electrode. The experiment was carried out at a room temperature of $25^{\circ} \mathrm{C}$. The polarization curve was analyzed by linear voltammetry. The working parameters were set as follows: scanning range $-500 \sim 500 \mathrm{mV}$ and scanning speed $0.5 \mathrm{mV} / \mathrm{s}$. Data were processed by the ModuLab software (version 2.0).

\section{Results and Discussion}

Figure 1 is a (scanning electron microscope) SEM image of the aluminum powder and carbon fibers after mechanical mixing. The spherical aluminum powder is uniformly distributed in the carbon fiber. The aluminum powder has a particle size range of 20-100 $\mu \mathrm{m}$. Carbon fibers were rod-shaped with a diameter of $6 \mu \mathrm{m}$ and a length of 30-70 $\mu \mathrm{m}$.

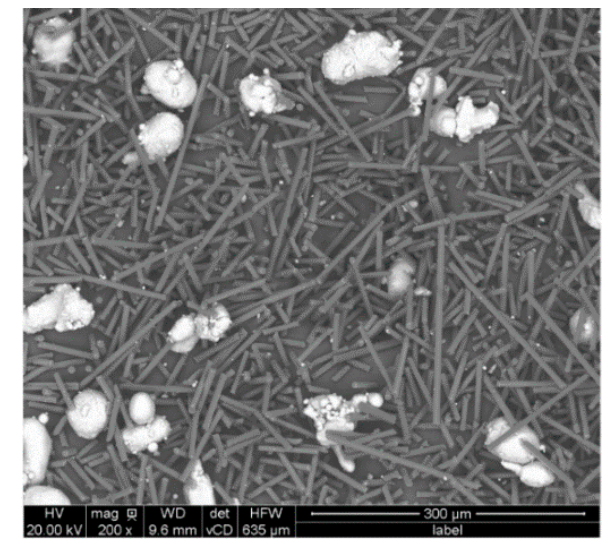

(a)

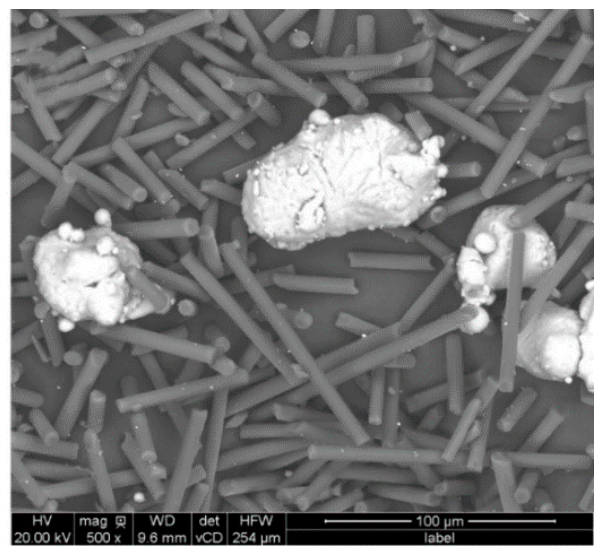

(b)

Figure 1. SEM morphology of aluminum powder and carbon fiber powder after ball mixing; (a) 200x magnification and (b) $500 \times$ magnification. 
The surface microstructure of the Al-CF composite coating is shown in Figure 2. It can be seen that the surface of the coating is staggered with rod-shaped carbon fibers and flat particles, but only a small amount of carbon fibers are exposed on the surface of the coating. There are flat particles on the surface of the pure aluminum coating of the control group and the flat particles are stacked on each other to form a dense coating.

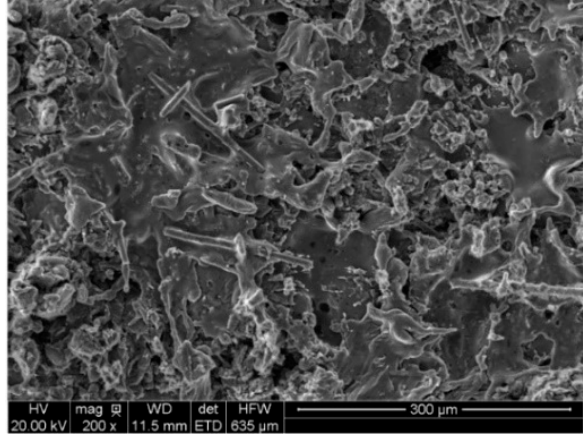

(a)

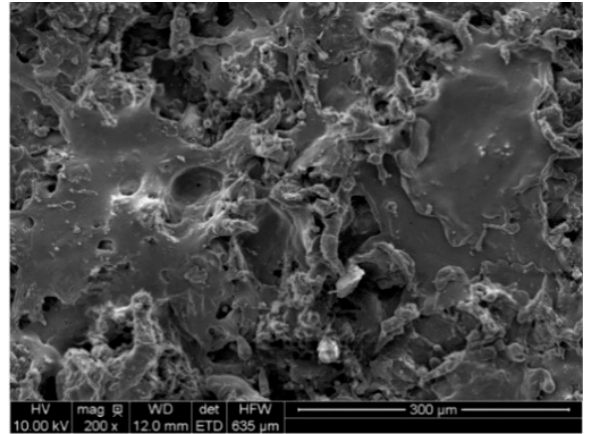

(b)

Figure 2. Surface views of arc sprayed aluminum-based coatings; (a) surface morphologies of the as-deposited Al-CF coatings deposited on the substrate; (b) surface morphologies of the as-deposited Al coatings deposited on the substrate.

Figure 3 is cross-sectional SEM images of the Al-CF composite coating. It can be seen that carbon fibers (the black parts in the images) are dispersed and distributed inside the coating, and there is no obvious flat particle interface in the coating. The coating is dense with few pores. These structural features further suggest the feasibility of arc spraying construction of the Al-CF coating, and the cored wire facilitates the deposition of $\mathrm{CF}$ during the spraying. It is known that during the spraying, $\mathrm{CF}$ does not encounter melting, which usually triggers difficulties in the deposition of $\mathrm{CF}$ on the substrate or pre-coating, for the rebounding of $\mathrm{CF}$ is expected upon impingement. The enwrapping state of $\mathrm{Al}-\mathrm{CF}$ particles with $\mathrm{CF}$ being wrapped by molten $\mathrm{Al}$ during the spraying effectively prevents the rebounding of $\mathrm{CF}$. On the other hand, co-existence of $\mathrm{CF}$ in the coating strengthens the cohesion of $\mathrm{Al}$ splats, giving rise to a lowered porosity.

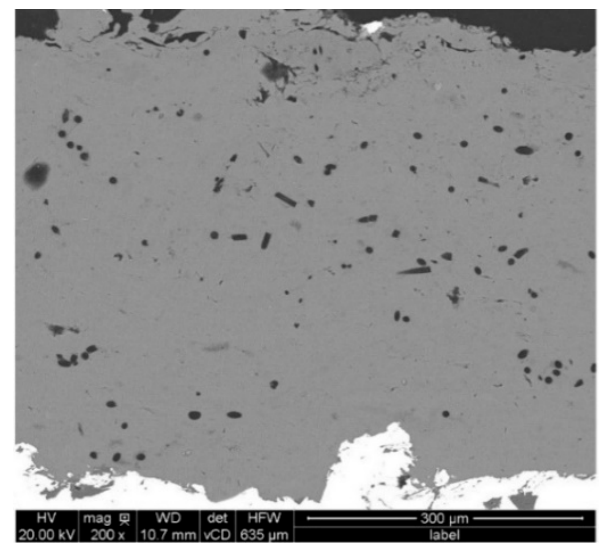

(a)

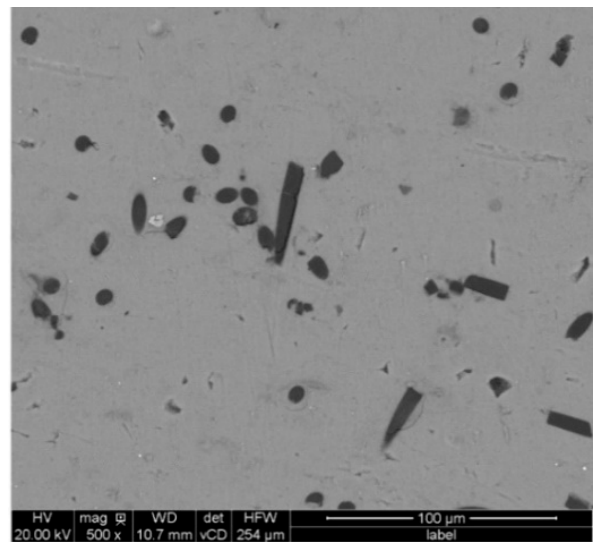

(b)

Figure 3. Cross-sectional SEM views of the as-deposited Al-CF coatings deposited on the substrate; (a) 200× magnification and (b) 500× magnification.

The result of the neutral salt spray test after $720 \mathrm{~h}$ is shown in Figure 4. Slight differences in colors and topographical morphology are seen for the $\mathrm{Al}$ coating and the Al-CF coating. No obvious corrosion products were observed on the surface of the pure aluminum and Al-CF composite coatings, 
and no obvious corrosion behavior occurred. However, red-brown corrosion products were observed on the surface of the uncoated Q235 substrate, and the rust was obvious, indicating that obvious corrosion behavior had occurred. The results show that both pure aluminum and Al-CF composite coatings have good corrosion resistance. Addition of an appropriate amount of carbon fibers into the aluminum coating system will not affect the original excellent corrosion resistance. Yet, the optimum concentration of CF in the coatings has to be determined, which is part of our ongoing research efforts.

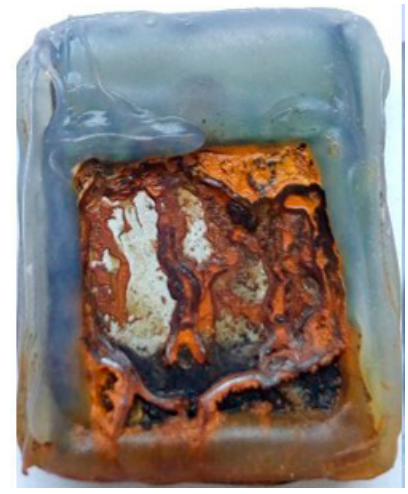

(a)

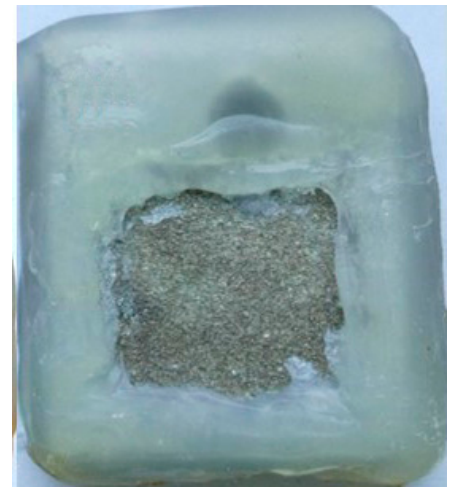

(b)

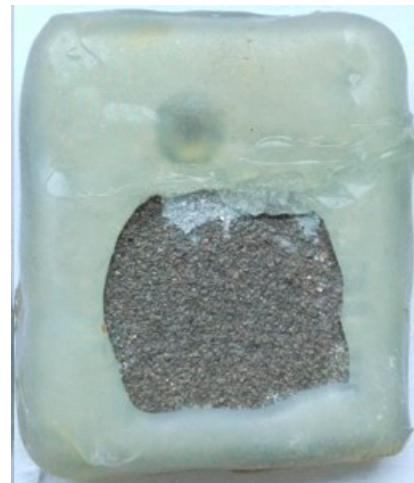

(c)

Figure 4. The digital photos of the coatings after $720 \mathrm{~h}$ of neutral salt spray test (NSS test) showing effective protection of the coatings against corrosion ((a): mild steel plate without coating, (b): the Al coating, and (c): the Al-CF coating).

The samples after the neutral salt spray test were further examined by SEM and are shown in Figure 5. Thickness of corrosion layer covered on Al and Al-CF coating surfaces is obviously less than that of the Q235 carbon steel surface. According to the SEM analyses, both the Al and the Al-CF coatings showed a presence of the corrosive layer (mainly aluminum hydroxide), which is attributed to the corrosion of $\mathrm{Al}$ (common phenomenon for $\mathrm{Al}$ coating during neutral salt spray testing). It is shown that the thickness of the corrosion layer of the Q235 carbon steel substrate without coating protection reaches $107 \mu \mathrm{m}$, while the thickness of the pure aluminum corrosion layer and Al-CF composite coating is only 22 and $29 \mu \mathrm{m}$, respectively. Compared with the carbon steel substrate, the pure aluminum coating and the Al-CF coating both show good corrosion resistance and play a good protective role. Compared with metallic elements, CFs are chemically inert and much more stable in a corrosion environment. CFs have much better corrosion resistance than the $\mathrm{Al}$ matrix, which in turn can reduce the degree of corrosion [18].

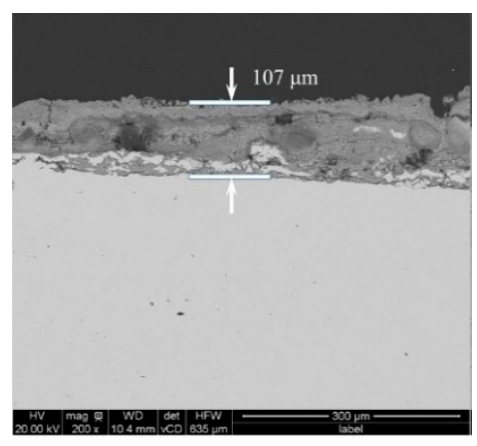

(a)

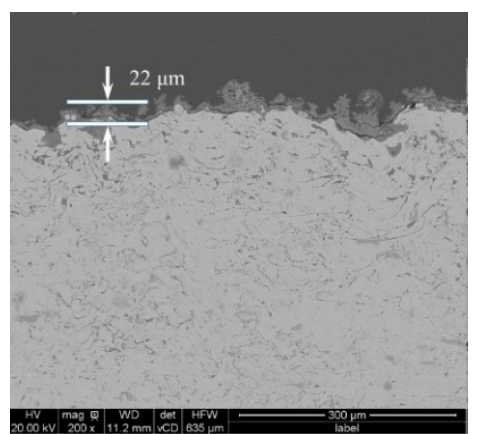

(b)

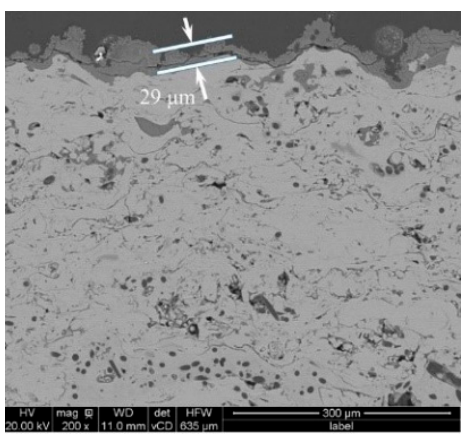

(c)

Figure 5. Cross-sectional morphology of the coatings after the corrosion testing showing the corrosion occurred on their top layer; SEM images of the cross-sections of (a) mild steel substrate, (b) Al coating, and (c) Al-CF coating subjected to a neutral salt spray test for $720 \mathrm{~h}$. 
Figure 6 and Table 2 show the comparison of electrochemical polarization curves and detailed parameters of coating samples. The corrosion potential of the pure aluminum coating sample is $-1.048 \mathrm{~V}$, the corrosion potential of the Al-CF coating sample is $-1.064 \mathrm{~V}$, and the corrosion potential of the Q235 substrate is $-0.8304 \mathrm{~V}$. In addition, the corrosion current of the pure aluminum coating is $8.278 \times 10^{-6} \mathrm{~A}$, the corrosion current of the Al-CF coating is $1.266 \times 10^{-5} \mathrm{~A}$, and the corrosion current of the Q235 substrate is $1.118 \times 10^{-6} \mathrm{~A}$. It is known that the corrosion current reflects the corrosion rate of the sample. The larger the corrosion current, the faster the corrosion rate. The higher the corrosion potential, the smaller the tendency for corrosion [6]. After addition of carbon fibers to the aluminum coating, there is no obvious change in corrosion resistance. Combined with the salt spray test results, the Al-CF coating shows good corrosion resistance.

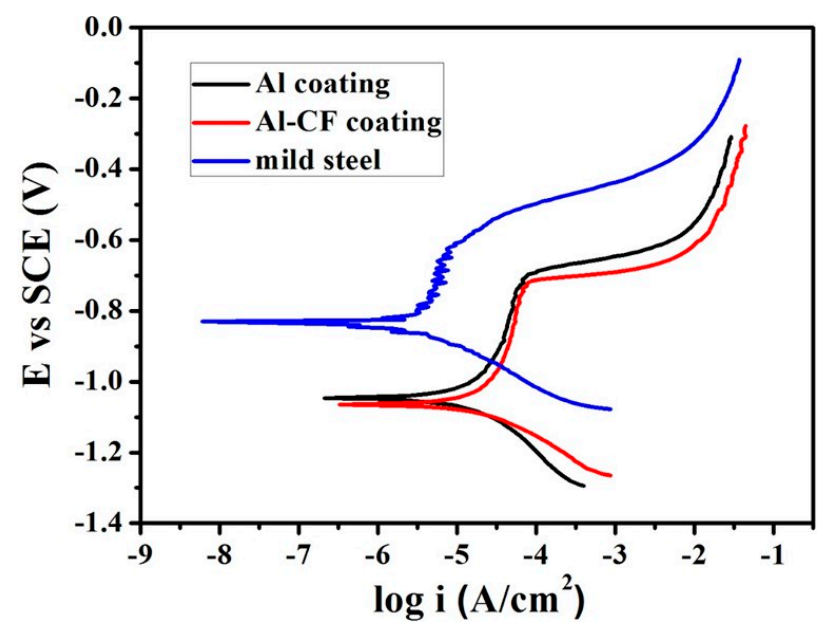

Figure 6. Potentiodynamic polarization curves for the pure Al coating, the Al-CF coating and mild steel plate without coating measured in $3.5 \mathrm{wt} . \% \mathrm{NaCl}$ solution.

Table 2. Electrochemical characteristics for the pure $\mathrm{Al}$ coating, the Al-CF coating and mild steel plate without coating measured in $3.5 \mathrm{wt} . \% \mathrm{NaCl}$ solution.

\begin{tabular}{ccc}
\hline Samples & Corrosion Potential $\left(E_{\text {corr }}\right)(\mathrm{V} / \mathrm{SCE})$ & Corrosion Current Density $\left(I_{\text {corr }}\right)\left(\mathrm{A} / \mathbf{c m}^{2}\right)$ \\
\hline Al coating & -1.048 & $8.278 \times 10^{-6}$ \\
Al-CF coating & -1.064 & $1.266 \times 10^{-5}$ \\
mild steel & -0.8304 & $1.118 \times 10^{-6}$ \\
\hline
\end{tabular}

From the perspective of the potential polarization curve, it is noted that aluminum is more active than iron and is more prone to corrosion in the early stages of corrosion. As the corrosion time increases, this layer act as a barrier protecting the Al-based coatings from the penetration of aggressive solutions, giving rise to the enhanced corrosion resistance. Combined with previous experimental results in Figures 4 and 5, a dense oxide film is formed on the coating surface to further prevent the corrosion from deepening and provides a good barrier effect.

Figure 7 shows the analysis of the impedance spectra of pure aluminum coatings and $\mathrm{Al}-\mathrm{CF}$ composite coatings. Among them (Figure $7 \mathrm{a}, \mathrm{b}$ ), it can be clearly found that with the increase in time, the impedance arcs of the two coatings become significantly larger, indicating that the resistance of the corrosion reaction increases. Because a dense oxide film is formed on the surface of the aluminum coating, the corrosion rate slows down. In Figure 7c,d (Bode diagrams), the pure $\mathrm{Al}$ coating and Al-CF composite coating both have a high impedance modulus and phase angle. It indicates that both coatings have good corrosion resistance. 


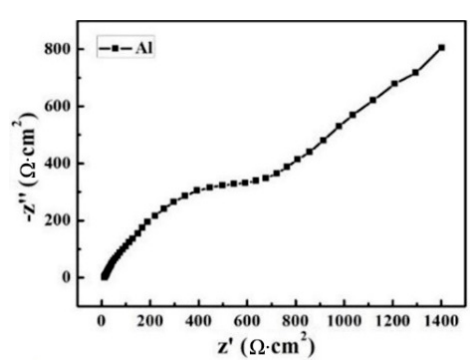

(a)

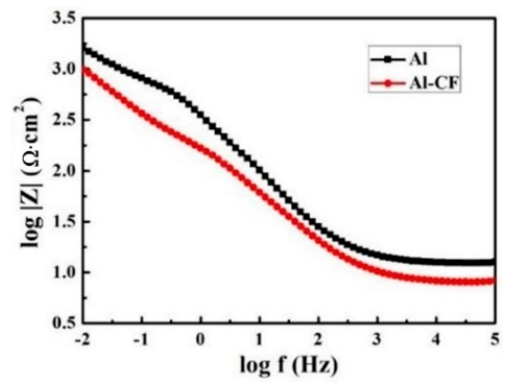

(c)

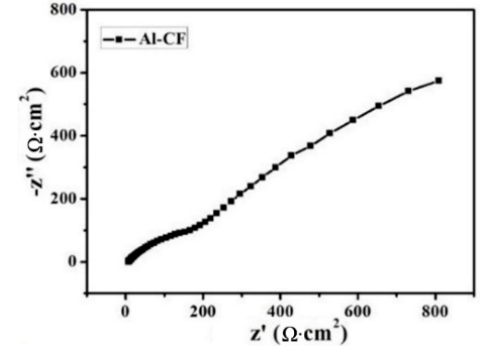

(b)

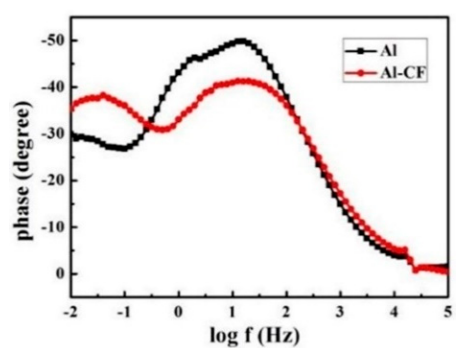

(d)

Figure 7. Electrical impedance spectroscopy (EIS) of Al coating and Al-CF composite coating; (a) Nyquist plots of the Al coating, (b) Nyquist plots of the Al-CF coating, and (c,d) bode plots of the Al coating and the Al-CF coating.

Figure 8a shows the friction coefficient curve of the Al-CF coating. It can be seen that the friction coefficient of the pure aluminum coating dropped from 0.7 to about 0.4 with time, and then remained stable, while the Al-CF composite coating dropped from 0.76 to about 0.2 , and then remained stable. The high friction coefficient at the beginning of the test was mainly due to the large surface roughness of the sample. The surface roughness decreased as the test progresses, and the friction coefficient also decreased. Figure $8 \mathbf{b}$ is a statistical diagram of the coating wear rate. The wear rate of the pure aluminum coating is about $2.0 \times 10^{-3} \mathrm{~mm}^{3} /(\mathrm{N} \cdot \mathrm{m})$, while that of the Al-CF composite coating is around $8 \times 10^{-4} \mathrm{~mm}^{3} /(\mathrm{N} \cdot \mathrm{m})$, showing significant improvement of wear resistance of the composite coating. The addition of carbon fiber results in a significant reduction in the friction coefficient and friction reduction effect. This is mainly due to the good lubrication and anti-wear properties of carbon fibers.

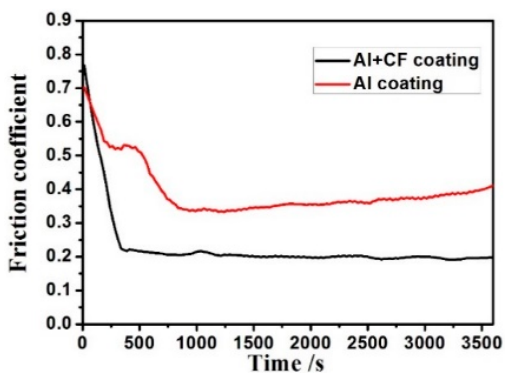

(a)

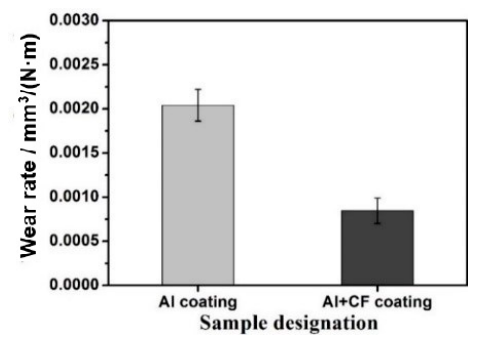

(b)

Figure 8. Wear testing results of $\mathrm{Al}$ coating and Al-CF composite coating, (a) friction coefficient curves, and (b) wear rate.

It should be noted that the results reported in this paper just give a preliminary idea of the effect of the addition of CFs on the performances of the Al-based coatings. Interestingly we noted that the addition of $\mathrm{CFs}$ can enhance the anti-wear performances of the $\mathrm{Al}$ coatings (mostly through reducing the wear coefficient), and it did not remarkably deteriorate the anti-corrosion performances of the 
coatings. These findings inspired us to make further investigations into the detailed mechanisms of the promoted anti-wear performances, as well as the corrosion behaviors of the CF-added coatings.

\section{Conclusions}

In this paper, an $\mathrm{Al}-\mathrm{CF}$ composite coating was prepared by arc spraying powder core wire technology and shows good corrosion resistance. According to the requirement of self-lubricating and anti-friction, the addition of carbon fibers to the coating provides a good anti-friction effect. Comprehensive analysis of the microstructure, electrochemical analysis, corrosion resistance, and friction properties of the two coatings was carried out using a variety of characterization methods.

- After $720 \mathrm{~h}$ of salt spray tests, no obvious corrosion product appeared on the coating surface, and the thickness of the cross-section corrosion layer of the pure aluminum coating and the Al-CF coating with carbon fiber was comparable and significantly lower than that of the Q235 carbon steel. The pure aluminum coating and the Al-CF coating showed good corrosion resistance, while the carbon steel substrate without coating protection was severely corroded in the salt spray test.

- The electrochemical behavior of the coating was tested by electrochemical testing, and its corrosion resistance was analyzed. After addition of carbon fibers, the corrosion potential of the coating decreased from -1.048 to $-1.064 \mathrm{~V}$, and the corrosion current increased from $8.278 \times 10^{-6} \mathrm{~A}$ to $1.266 \times 10^{-5} \mathrm{~A}$. The corrosion resistance of the Al-CF coating is slightly weakened but not much different compared with the aluminum coating. The former one still has good corrosion resistance.

- The wear performance of the coating was analyzed by a friction and wear testing machine. After addition of carbon fibers to the coating, the friction coefficient decreased from 0.4 to 0.2 , and the wear rate of the coating decreased from $2 \times 10^{-3} \mathrm{~mm}^{3} /(\mathrm{N} \cdot \mathrm{m})$ to $8 \times 10^{-4} \mathrm{~mm}^{3} /(\mathrm{N} \cdot \mathrm{m})$. A significant friction reduction effect was obtained.

Author Contributions: Conceptualization, S.F. and Z.H.; methodology, S.F. and Z.H.; software, S.H.; validation, S.F. and Z.H.; formal analysis, S.F., J.Z. and S.H.; investigation, S.F., J.Z. and S.H.; data curation, S.F. and J.Z.; writing-original draft preparation, S.F.; writing-review and editing, Z.H.; supervision, W.L.; project administration, Z.H.; funding acquisition, W.L. All authors have read and agreed to the published version of the manuscript.

Funding: This research was funded by China Southern Power Grid Co., Ltd. Liuzhou Bureau of EHV Transmission Company, Grant No. CGYKJXM2017039.

Acknowledgments: The authors thank Hua Li, Botao Zhang and Yi Liu from Ningbo Institute of Materials Technology and Engineering, Chinese Academy of Sciences, for the SEM measurements.

Conflicts of Interest: The authors declare no conflict of interest regarding the publication of this article.

\section{References}

1. Rodriguez, R.; Paredes, R.S.C.; Wido, S.H.; Calixto, A. Comparison of aluminum coatings deposited by flame spray and by electric arc spray. Surf. Coat. Technol. 2007, 202, 172-179. [CrossRef]

2. Rogers, F.S. Thermal spray for commercial shipbuilding. J. Therm. Spray Technol. 1997, 6, 291-293. [CrossRef]

3. Kuroda, S.; Kawakita, J.; Takemoto, M. An 18-year exposure test of thermal-sprayed Zn, Al, and Zn-Al coatings in marine environment. Corrosion 2006, 62, 635-647. [CrossRef]

4. Esfahani, E.A.; Salimijazi, H.; Golozar, M.A.; Mostaghimi, J.; Pershin, L. Study of corrosion behavior of arc sprayed aluminum coating on mild steel. J. Therm. Spray Technol. 2012, 21, 1195-1202. [CrossRef]

5. Wood, R.J.K.; Speyer, A.J. Erosion-corrosion of candidate HVOF aluminium-based marine coatings. Wear 2004, 256, 545-556. [CrossRef]

6. Qing, T.; Zhi, S.; Chun-long, Y.;Yun-qi, A. Impact mechanism of nano-sized $\mathrm{TiO}_{2}$ and $\mathrm{SiO}_{2}$ on corrosion resistance of electric arc spraying sealing coat. Procedia Earth Planet. Sci. 2009, 1, 851-856.

7. Luo, X.; He, D.Y.; Zhou, Z.; Wang, G.H.; Wang, Z.J.; Wu, X. Particle and coating formation characteristics during arc spraying with $\mathrm{AlMg} / \mathrm{Al}_{2} \mathrm{O}_{3}$ cored wires. Surf. Technol. 2018, 47, 191-196. (In Chinese) 
8. Xu, B.S.; Zhu, X.X.; Ma, S.N.; Zhang, W.; Liu, W.M. Sliding wear behavior of Fe-Al and Fe-Al/WC coatings prepared by high velocity arc spraying. Wear 2004, 257, 1089-1095. [CrossRef]

9. Li, R.; He, D.Y.; Zhou, Z.; Wang, Z.J.; Song, X.Y. Wear and high temperature oxidation behavior of wire arc sprayed iron based coatings. Surf. Eng. 2014, 30, 784-790. [CrossRef]

10. Bobzin, K.; Oete, M.; Linke, T.F.; Schulz, C. Corrosion of wire arc sprayed ZnMgAl. Mater. Corros. 2015, 66, 520-526. [CrossRef]

11. Sheppard, P.; Koiprasert, H. Effect of W dissolution in NiCrBSi-WC and NiBSi-WC arc sprayed coatings on wear behaviors. Wear 2014, 317, 194-200. [CrossRef]

12. Li, Z.R.; Li, D.Y.; Zhang, N.N.; Huang, H.; Wang, X. Wear mechanism of iron-based alloy coating by arc spraying. J. Iron Steel Res. Int. 2016, 23, 834-841. [CrossRef]

13. Li, R.; Zhou, Z.; He, D.Y.; Zhao, L.D.; Song, X.Y. Microstructure and high-temperature oxidation behavior of wire arc sprayed Fe-based coatings. Surf. Coat. Technol. 2014, 251, 186-190. [CrossRef]

14. Zhang, X.; Wang, Z.H.; Lin, J.R.; Zhou, Z.H. A study on high temperature oxidation behavior of high-velocity arc sprayed Fe-based coatings. Surf. Coat. Technol. 2015, 283, 255-261. [CrossRef]

15. Liu, S.G.; Wu, J.M.; Zhang, S.C.; Rong, S.J.; Li, Z.Z. High temperature erosion properties of arc-sprayed coatings using various cored wires containing Ti-Al intermetallics. Wear 2007, 262, 555-561. [CrossRef]

16. Wang, Y.; Sun, C.; Sun, J.B.; Zhao, W.M.; Dong, L.X.; Li, L.Y.; Meng, F.G. Erosion behavior of arc sprayed FeTi/CrB MMC coating at elevated temperature. Surf. Coat. Technol. 2015, 262, 141-147. [CrossRef]

17. Liu, L.; Li, W.W.; Tang, Y.P.; Shen, B.; Hu, W.B. Friction and wear properties of short carbon fiber reinforced aluminum matrix composites. Wear 2009, 266, 733-738. [CrossRef]

18. Lei, J.B.; Shi, C.; Zhou, S.F.; Gu, Z.J.; Zhang, L.C. Enhanced corrosion and wear resistance properties of carbon fiber reinforced Ni-based composite coating by laser cladding. Surf. Coat. Technol. 2018, 334, $274-285$. [CrossRef]

19. ASTM B117. Standard Practice for Operating Salt Spray (Fog) Apparatus; ASTM International: West Conshohocken, PA, USA, 2007.

Publisher's Note: MDPI stays neutral with regard to jurisdictional claims in published maps and institutional affiliations.

(C) 2020 by the authors. Licensee MDPI, Basel, Switzerland. This article is an open access article distributed under the terms and conditions of the Creative Commons Attribution (CC BY) license (http://creativecommons.org/licenses/by/4.0/). 